\title{
Novel use of a retroaortic innominate vein in cavopulmonary anastomosis
}

\author{
Ravi Agarwal, MCh, ${ }^{a}$ Ganapathy Subramaniam Krishnan, MCh, ${ }^{a}$ Snehal Kulkarni, DNB, ${ }^{b}$ Kinnari Bhatt, MD, ${ }^{c}$ \\ and Kotturathu Mammen Cherian, FRACS, ${ }^{a}$ Tamil Nadu, India
}

A retroaortic innominate vein is a rare condition with an incidence of $0.2 \%$ to $1 \%$ among congenital cardiac anomalies. $^{1,2}$ Its association with right aortic arch, high left aortic arch, and pulmonary atresia or stenosis is well recognized. ${ }^{3}$ We present a child with tricuspid atresia and pulmonary atresia with bifurcation stenosis of confluent pulmonary arteries (Figure 1). The child also had a right aortic arch. The parallel course of the retroaortic innominate vein with the pulmonary artery was used in pulmonary artery reconstruction by creating a wide side-to-side anastomosis (Figure 2).

\section{Clinical Summary}

The child was given a diagnosis of tricuspid atresia and pulmonary atresia at birth. He underwent placement of a left modified Blalock-Taussig shunt at day 1 of life. He was initially doing well, and then he presented at 6 months of life with increasing cyanosis. A central shunt from the aorta to the right pulmonary artery was placed through a sternotomy at another center. At 9 months of age, when he presented with increasing cyanosis, it was found that the central aortopulmonary shunt had become blocked and that there was narrowing of the left Blalock-Taussig shunt. A narrowed patent ductus was found supplying the right pulmonary artery. The patent ductus arteriosus (PDA) was stented, with the stent extending into the right pulmonary artery.

When he presented to us at 1 year and 5 months of age, he had a patent but narrowed left Blalock-Taussig shunt, a blocked aortoright pulmonary shunt and a stented PDA supplying the right pulmonary artery, which had narrowed. He had an oxygen saturation of $72 \%$ on room air. There was severe stenosis of the pulmonary artery bifurcation at the site of PDA insertion (Figure 1). $\mathrm{He}$ had a right aortic arch. A computed tomographic angiogram revealed that he had a retroaortic innominate vein. A bidirectional Glenn procedure with pulmonary artery reconstruction was planned. After induction, a venous cannula in the left jugular vein was placed to detect any compression of the retroaortic innominate vein. The right and left jugular venous catheters showed equal

From the Departments of Pediatric Cardiac Surgery, ${ }^{a}$ Pediatric Cardiology, and Pediatric Cardiac Anesthesia, ${ }^{c}$ Frontier Lifeline Hospital, International Centre for Cardiothoracic and Vascular disease, Tamil Nadu, India.

Received for publication Jan 22, 2006; revisions received Jan 22, 2006; accepted for publication Feb 15, 2006.

Address for reprints: Ganapathy Subramaniam Krishnan, MCh, 35/1 P.C.O Road Egmore, Chennai, Tamil Nadu-600008 (E-mail: ganapathysubramaniamk@ gmail.com).

J Thorac Cardiovasc Surg 2006;132:166-7

$0022-5223 / \$ 32.00$

Copyright @ 2006 by The American Association for Thoracic Surgery doi:10.1016/j.jtcvs.2006.02.045

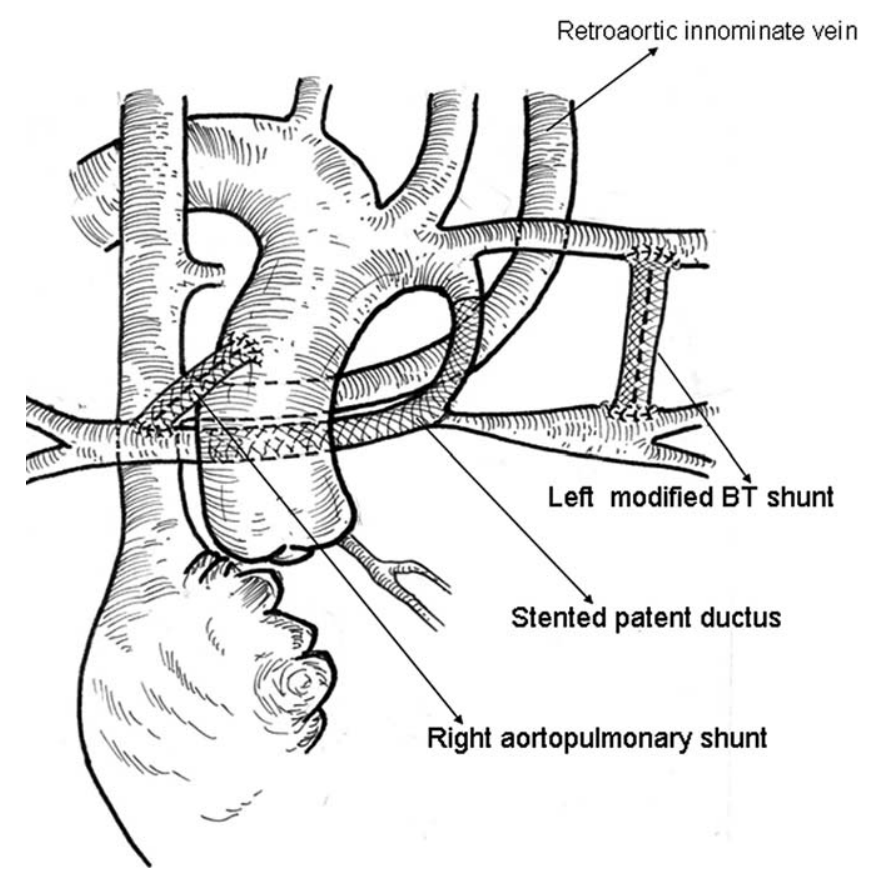

Figure 1. Patient with tricuspid atresia, pulmonary atresia with a left modified Blalock-Taussig (BT) shunt, a stented patent ductus arteriosus, and blocked central aortopulmonary shunt to the right pulmonary artery.

pressures of $10 \mathrm{~mm} \mathrm{Hg}$. A redo median sternotomy was performed, and the aorta and right atrium were cannulated. All the systemic pulmonary shunts were controlled, and the patient was cooled to $18^{\circ} \mathrm{C}$. The retroaortic innominate vein was dissected. It was found coursing just above the left pulmonary artery behind the PDA and inserting into the superior vena cava just above its junction with right atrium. The aorta was transected to provide unimpeded visualization of the pulmonary artery bifurcation. The pulmonary artery was opened, and the previous stent was removed piecemeal. The pulmonary artery was opened across the stenosed portion into the right and left pulmonary artery. The retroaortic innominate vein was opened parallel to the pulmonary artery from its insertion into the superior vena cava and anastamosed side to side, with the pulmonary artery providing a wide, unimpeded venous drainage into the pulmonary arteries and at the same time augmenting the stenosed portion of the pulmonary artery bifurcation (Figure 2). The aorta was reanastomosed, and the patient was weaned off cardiopulmonary bypass. The oxygen saturation was $87 \%$ with a fraction of inspired oxygen of $60 \%$, and the left and 


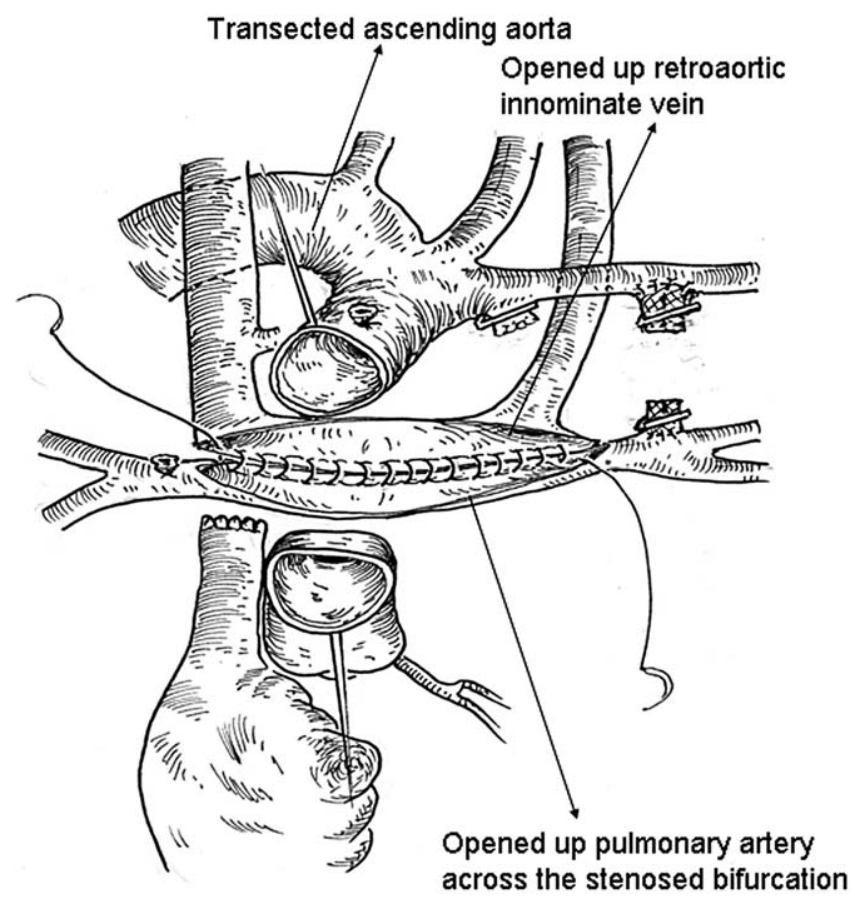

Figure 2. Control of all central aortopulmonary shunts. Transection of the aorta was performed to gain adequate exposure for pulmonary artery reconstruction. A side-to-side anastomosis of the opened retroaortic innominate vein and pulmonary artery was created.

right jugular venous pressures were similar $(14 \mathrm{~mm} \mathrm{Hg})$. He required no inotropic support and had an uneventful postoperative recovery.

\section{Discussion}

Embryologically, the retroaortic innominate vein represents the persistent inferior transverse capillary plexus between the anterior cardinal veins. The descent of the aortic arch and development of the pulmonary artery normally causes regression of this capillary plexus. This explains the association of the right aortic arch, the high aortic arch, and pulmonary atresia or stenosis with the retroaortic innominate vein. ${ }^{3,4}$ The significance of the retroaortic vein while performing cavopulmonary anastomosis is the concern that the innominate vein might be compressed by the aorta. Reimplantation of the innominate vein anterior to the aorta or a separate anastomosis of the left brachiocephalic vein with the left pulmonary artery has been recommended to prevent compression. ${ }^{4,5}$

Our patient provided a unique opportunity in which there was pulmonary artery bifurcation stenosis in a single-ventricle situation with a retroaortic innominate vein. The parallel course of the vein with the pulmonary artery was used in constructing a wide sideto-side anastomosis. This provided not only an unimpeded venous drainage into the pulmonary arteries but also helped in augmenting the stenosed bifurcation of the pulmonary artery (Figure 2). The postoperative pressure measurement and echocardiography confirmed that there was no compression of the vein. To our knowledge, this is the first reported instance of the use of a retroaortic innominate vein for pulmonary artery reconstruction and cavopulmonary anastomosis.

We thank Mr Dhanapalan for his assistance with the illustrations.

\section{References}

1. Choi JY, Jung MJ, Kim YH, Noh CI, Yun YS. Anomalous subaortic position of the brachiocephalic vein (innominate vein): an echocardiographic study. Br Heart J. 1990;64:385-7.

2. Gerlis LM, Ho SY. Anomalous subaortic position of the brachiocephalic (innominate) vein: a review of published reports and report of three new cases. Br Heart J. 989;61:540-5.

3. Konstantinov EI, Van Arsdell GS, O'Blenes S, Roy N, Campbell A. Retroaortic innominate vein with coarctation of the aorta: surgical repair and embryology review. Ann Thorac Surg. 2003;75:1014-6.

4. Chen SJ, Kao-Lang Liu KL, Chen HY, Chiu IS, Lee WJ, Wu MH, et al. Anomalous brachiocephalic vein: CT, embryology, and clinical implications. AJR Am J Roentgenol. 2005; 184:1235-40.

5. Koutas TC, Wernovsky G, Slack MC, Weinberg PM, Spray TL. Surgical management of tricuspid atresia and anomalous left brachiocephalic vein. Ann Thorac Surg. 1998;65:1770-2. 